\title{
USO DE REVESTIMENTOS À BASE DE DEXTRINA NA CONSERVAÇÃO PÓS-COLHEITADE MANGA 'TOMMY ATKINS'`
}

\author{
THALITAPASSOS RIBEIRO², MARIAAUXILIADORACOÊLHO DE LIMA ${ }^{3}$, \\ DANIELLY CRISTINAGOMES DATRINDADE 4 , \\ ANA CRISTINA NASCIMENTO DOS SANTOS², ANDRÉIAAMARIZ²
}

RESUMO - Este trabalho avaliou a qualidade de manga ‘Tommy Atkins’, colhida em estádio de maturação 2, após a aplicação de revestimentos com diferentes concentrações de dextrina associadas ou não a fonte lipídica. Foram realizados dois experimentos. No primeiro, os tratamentos consistiram em: aplicação de revestimento (controle; $1,5 \%$ de dextrina; $1,5 \%$ de dextrina + 0,4\% de óleo-de-girassol; 3,0\% de dextrina e $3,0 \%$ de dextrina $+0,4 \%$ de óleo-de-girassol) e armazenamento durante $0 ; 10$ e 20 dias sob refrigeração $\left(11,7 \pm 3,1^{\circ} \mathrm{C}\right.$ e $\left.79 \pm 8 \% \mathrm{UR}\right)$, seguido de $3 ; 6$ e 8 dias em temperatura ambiente $\left(21,3 \pm 2,6^{\circ} \mathrm{C}\right.$ e $48 \pm 8 \%$ UR). No segundo experimento, foram estudados os revestimentos: controle e soluções aquosas de 2 ; 3 e $4 \%$ de dextrina, contendo óleo-de-girassol a $0,4 \%$. Após a aplicação, as frutas foram armazenadas sob refrigeração $\left(11,7 \pm 3,1^{\circ} \mathrm{C}\right.$ e $87 \pm 6 \%$ UR) para avaliação aos 0 ; 10 e 20 dias, ao final dos quais foram transferidas para temperatura ambiente $\left(23,1 \pm 2,1^{\circ} \mathrm{C}\right.$ e $56 \pm 7 \%$ UR) por mais 3 ; 6 ; 8 e 10 dias. O delineamento experimental utilizado nos dois estudos foi o inteiramente casualizado, em fatorial, com quatro repetições. O uso dos revestimentos reduziu a perda de massa das frutas, sendo que a concentração de $2 \%$ contendo óleo-degirassol atrasou a maturação, observando-se limitação da perda de firmeza e da degradação de ácidos orgânicos, atraso no aumento do conteúdo de substâncias pécticas e preservação da aparência, formando película uniforme a olho nu.

Termos para indexação: conservação pós-colheita, película comestível, qualidade, vida útil.

\section{USE OF DEXTRIN-BASED COATINGS ON POSTHARVEST CONSERVATION OF 'TOMMY ATKINS’ MANGO FRUIT}

\begin{abstract}
This study evaluated the quality of 'Tommy Atkins' mango fruit harvested at maturity stage 2 after coating application with different dextrin concentrations associated or not to a lipid substance. Two experiments were carried out: in the first one, the treatments consisted of coating application (control; dextrin $1.5 \%$; dextrin $1.5 \%$ + sunflower oil $0.4 \%$; dextrin $3.0 \%$, and dextrin $3.0 \%+$ sunflower oil $0.4 \%$ ) and storage for 0,10 and 20 days under refrigeration $\left(11.7 \pm 3.1^{\circ} \mathrm{C}\right.$ and $\left.79 \pm 8 \% \mathrm{RH}\right)$, followed by 3,6 and 8 days at room temperature $\left(21.3 \pm 2.6^{\circ} \mathrm{C}\right.$ and $\left.48 \pm 8 \% \mathrm{RH}\right)$. In the second experiment, control and coatings with aqueous solutions of dextrin 2,3 and $4 \%$, containing sunflower oil $0.4 \%$, were studied. After the application, the fruits were stored under refrigeration $\left(11.7 \pm 3.1^{\circ} \mathrm{C}\right.$ and $\left.87 \pm 6 \% \mathrm{RH}\right)$ for evaluation for 0,10 and 20 days, when they were transferred to room temperature $\left(23.1 \pm 2.1^{\circ} \mathrm{C}\right.$ and $\left.56 \pm 7 \% \mathrm{RH}\right)$ for $3,6,8$ and 10 days. A completely random design was used in a factorial scheme, with four replicates. The use of coatings reduced fruit weight loss but only dextrin $2 \%$ with sunflower oil delayed the maturation, showing limitation on firmness loss and organic acids breakdown, delay on the increase of pectic substances content and preservation of fruit appearance, with a uniform visible film.
\end{abstract}

IndexTerms: postharvest conservation, edible coating, quality, storage life.

\footnotetext{
${ }^{1}$ (Trabalho 101-08). Recebido em: 24-04-2008. Aceito para publicação em:12-02-2009. Apoio: Banco do Nordeste do Brasil S.A.

${ }^{2}$ Graduanda em Biologia, Bolsista PIBIC-CNPq/FACEPE, Universidade de Pernambuco/Faculdade de Formação de Professores de Petrolina, BR 203, Km 02, 56300-000, Petrolina-PE. E-mai: thallyta.passos@yahoo.com.br, acns7@yahoo.com.br, aamariz@hotmail.com

${ }^{3}$ Dra., Pesquisadora, Embrapa Semi-Árido, BR 428, Km 152, Caixa postal 23, 56.302-970, Petrolina-PE. E-mail: maclima@cpatsa.embrapa.br

${ }^{4}$ Licenciada em Ciências Biológicas, laboratorista, Embrapa Semi-Árido. E-mail: danielly@cpatsa.embrapa.br
} 


\section{INTRODUÇÃO}

O Brasil tem excelentes condições climáticas para a exploração comercial da mangueira (Mangifera indica L.). No Nordeste, principalmente no Submédio São Francisco, a manga é um dos principais produtos da economia regional, com produção voltada para a exportação. Segundo dados da VALEXPORT (2008), em 2007, a região exportou 107.812 toneladas de manga, o que correspondeu a 93\% das exportações nacionais da fruta. Os resultados confirmam, portanto, o grande destaque da região no cenário agrícola nacional.

Os principais importadores da manga produzida no Brasil são a Europa e os Estados Unidos. Porém, nos últimos anos, o mercado japonês, apesar de pequeno, tem apresentado crescimento contínuo (Anuário Brasileiro da Fruticultura, 2007). Porém, os importadores relatam que as frutas não apresentam amadurecimento uniforme, e os consumidores requerem uma relação sabor/firmeza que é muito variável em mangas (Morais et al., 2002). Além disso, são registradas perdas pós-colheita em virtude, principalmente, da alta perecibilidade da fruta e do emprego de manuseio e técnicas de conservação inadequados.

Diante disto, faz-se necessária a adoção de técnicas que mantenham a qualidade e prolonguem a vida pós-colheita da manga. Entre elas, pode-se utilizar: refrigeração, que mantém o metabolismo em nível mínimo suficiente para conservar as células vivas e preservar a qualidade; atmosfera controlada (AC); e atmosfera modificada (AM). As duas últimas visam a prolongar a conservação por meio da alteração da concentração de gases disponível para a respiração durante o armazenamento, sendo que a AM implica menores custos (Wills et al., 2007).

A AM pode ser obtida com o uso de filmes plásticos, como polietileno de baixa densidade (PEBD) e cloreto de polivinila (PVC), ou de revestimentos à base de cera-de-carnaúba, polissacarídeos, proteínas e lipídios, entre outros. Quando revestidas de forma adequada, as frutas têm reduzida perda de umidade e menor incidência de microrganismos patogênicos, aumentando o período de conservação e melhorando a aparência pelo incremento do brilho superficial. No entanto, se o revestimento for muito espesso ou possuir baixa permeabilidade a oxigênio e dióxido de carbono, a fruta pode iniciar uma respiração anaeróbia, sofrendo desordens fisiológicas (Mota et al., 2006; Henrique et al., 2008).

Alguns estudos relatam a eficiência dos revestimentos, também denominados películas, na extensão da vida útil de mangas (Baldwin et al., 1999; Hoa \& Ducamp, 2008), tomates (Chiumarelli \& Ferreira, 2006), pêssegos (Oliveira \& Cereda, 2003) e goiabas (Lucena et al., 2003), entre outros.

A película de amido, em particular, é uma alternativa em potencial, por se tratar de um produto biodegradável, de baixo custo e que não causa impacto ambiental (Henrique et al., 2008), principalmente se comparada aos derivados do petróleo, como as embalagens de PVC e algumas ceras que, muitas vezes, apresentam polietileno em sua composição.

As soluções à base de amido são geralmente obtidas por meio da geleificação do composto em água aquecida até $70^{\circ} \mathrm{C}$, sob agitação constante, e posterior resfriamento até $15^{\circ} \mathrm{C}$ (Fontes et al., 2007). Por sua vez, a utilização da dextrina, um produto da degradação do amido, tem a vantagem de ser solúvel em água à temperatura ambiente, podendo ser usada como agente espessante, revestimento, adsorvedor, adesivo, formador de filmes, suplemento nutritivo, entre outras aplicações (White Junior et al., 2003). Apesar de suas potencialidades reconhecidas, ainda não existem relatos da aplicação de dextrina na conservação de frutas frescas. Contudo, em razão das propriedades mencionadas, é possível que, associada à refrigeração, possa aumentar a vida póscolheita de mangas ‘Tommy Atkins’ e contribuir para a melhoria da sua qualidade.

O presente trabalho objetivou avaliar a qualidade de mangas 'Tommy Atkins' após a aplicação de revestimentos com diferentes concentrações de dextrina, associadas ou não a fonte lipídica, em armazenamento refrigerado seguido de temperatura ambiente.

\section{MATERIAL E MÉTODOS}

Mangas ‘Tommy Atkins' foram colhidas em estádio de maturação 2 (casca de cor verde-clara no ápice da fruta e polpa levemente amarela), em pomares comerciais situados em Petrolina-PE, e transportadas ao Laboratório de Pós-Colheita, onde foram conduzidos dois experimentos, em períodos distintos. No laboratório, as frutas foram lavadas, tratadas com água clorada $\left(50 \mu \mathrm{g}^{-\mathrm{g}^{-1}}\right)$ e secas ao ambiente. Posteriormente, foram selecionadas com base na uniformidade de tamanho, sanidade e ausência de defeitos.

Experimento 1: Utilização de revestimentos à base de dextrina com ou sem óleo-de- girassol para conservação pós-colheita de manga 'Tommy Atkins'

Os revestimentos-controle: $1,5 \%$ de dextrina; 
1,5\% de dextrina $+0,4 \%$ de óleo-de- girassol; 3,0\% de dextrina e 3,0\% de dextrina $+0,4 \%$ de óleo-degirassol foram aplicados nas frutas por meio de pulverizador costal, a fim de aproximar-se das condições adotadas nos packinghouses em que são usados aspersores para aplicação de cera. Após a aplicação, as frutas foram armazenadas sob refrigeração $\left(11,7 \pm 3,1^{\circ} \mathrm{C}\right.$ e $79 \pm 8 \%$ UR) para avaliação aos $0 ; 10$ e 20 dias, quando foram transferidas para temperatura ambiente $\left(21,3 \pm 2,6^{\circ} \mathrm{C}\right.$ e $48 \pm 8 \%$ UR) por mais 3; 6 e 8 dias.

O delineamento experimental foi o inteiramente casualizado, em fatorial $5 \times 6$ (revestimento $\mathrm{x}$ tempo de armazenamento), com quatro repetições de três frutas.

As variáveis analisadas foram: a) perda de massa (\%), determinada pela diferença entre a massa no dia da colheita e no dia da avaliação; b) firmeza da polpa (N), determinada em penetrômetro manual, com ponteira de $8 \mathrm{~mm}$ de diâmetro; c) cor da casca, conforme escala proposta por EMEX (1998), em que 1 =verde-escuro, $2=$ verde-claro, $3=$ amarelo-claro predominante e 4= amarelo-alaranjado; d) teor de sólidos solúveis (SS, ${ }^{\circ}$ Brix), obtido em refratômetro digital (AOAC, 1992); e) acidez titulável (AT, \% ácido cítrico), determinada por titulometria com solução de NaOH 0,1 M (AOAC, 1992); f) aparência, avaliada usando a escala subjetiva de notas proposta por Lima et al. (2007), em que: $4=$ fruta isenta de manchas e com aparência fresca; $3=$ sinais de murcha inicial (perda de brilho e turgor) e/ou presença de manchas em até $5 \%$ da superfície da fruta; $2=$ manchas em 6 a $20 \%$ da superfície e/ou enrugamento inicial; $1=$ manchas em 21 a $40 \%$ da fruta e/ou avanço do enrugamento (intensidade moderada), e $0=$ manchas em mais de $40 \%$ da área da fruta e/ou enrugamento em intensidade severa e/ou podridão; e g) manchas vermelhas em torno das lenticelas, avaliadas com base nos mesmos limites da escala de notas da aparência.

Os dados foram submetidos à análise de variância. Quando os efeitos foram significativos, as médias dos revestimentos foram comparadas pelo teste de Tukey $(\mathrm{P} \leq 0,05)$, e as dos tempos de armazenamento, submetidas à análise de regressão polinomial. Havendo interação significativa, realizou-se o desdobramento dos revestimentos em cada tempo.

Experimento 2: Qualidade pós-colheita de manga 'Tommy Atkins' após aplicação de revestimentos de dextrina contendo óleo-degirassol

Neste estudo, foram testados os revestimentos: controle e soluções aquosas de dextrina a 2; 3 e 4\%, contendo óleo-de-girassol a 0,4\%, em aplicação com pulverizador manual. Após a aplicação, as frutas foram armazenadas sob

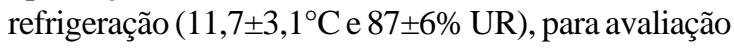
aos $0 ; 10$ e 20 dias, ao final dos quais foram transferidas para temperatura ambiente $\left(23,1 \pm 2,1^{\circ} \mathrm{C} \mathrm{e}\right.$ $56 \pm 7 \%$ UR) por mais 3; 6; 8 e 10 dias.

Odelineamento experimental foi o inteiramente casualizado, em fatorial $4 \times 7$ (revestimento $\mathrm{x}$ tempo de armazenamento), com quatro repetições de quatro frutas cada.

Neste experimento, foram avaliadas as mesmas variáveis do anterior, sendo que a cor da casca, medida na região verde, foi determinada em colorímetro, por meio dos atributos luminosidade (L), croma (C) e ângulo de cor (H). Em adição, determinouse o conteúdo de substâncias pécticas $\left(\mathrm{g} .100 \mathrm{~g}^{-1}\right)$, extraída seguindo a descrição de McReady \& McComb (1952), e quantificada conforme recomendação de Blumenkrantz \& Asboe-Hansen (1973).

A análise estatística dos dados seguiu os procedimentos adotados no experimento 1.

\section{RESULTADOS E DISCUSSÃO}

Experimento 1: Utilização de revestimentos à base de dextrina com ou sem óleo-de- girassol para conservação pós-colheita de manga 'Tommy Atkins'

A perda de massa e a firmeza da polpa apresentaram variações significativas durante 0 período estudado, notadamente a partir da mudança nas condições de armazenamento, ao $20^{\circ}$ dia (Figura $1 \mathrm{~A})$. A perda de massa, que era de $2,1 \%$, ao $10^{\circ}$ dia, atingiu $10,9 \%$, ao $28^{\circ}$ dia. No entanto, a menor perda de massa média, correspondente a 5,9\%, foi observada nas frutas revestidas com 3,0\% de dextrina + óleode-girassol (Figura 1B). Esse tratamento não diferiu daquele que usou a mesma concentração de dextrina sem o óleo-de-girassol.

Em geral, atribui-se à limitação da perda de massa em frutas revestidas à barreira formada pelo revestimento, a qual pode, inclusive, atrasar o amadurecimento. Essa permeabilidade à água varia conforme o tipo de revestimento, sendo menor para as ceras-de-carnaúba e relativamente maior para aqueles à base de polissacarídeos (Baldwin et al., 1999). Em maracujá-amarelo, a aplicação de revestimentos de cera de carnaúba reduziu a perda de massa, sendo a resposta ampliada quando esse tratamento foi associado ao uso de embalagem de plástico poliolefínico (Mota et al., 2006). Olivas et al. (2007) também observaram menor perda de massa em maçã pré-cortada revestida com alginato de sódio. 
Por sua vez, a firmeza da polpa foi reduzida desde valores de $72 \mathrm{~N}$, por ocasião da colheita, para $9 \mathrm{~N}$, aos 28 dias, não sendo influenciada pela aplicação dos revestimentos (Figura 1A). O amaciamento da polpa caracteriza a evolução da maturação de frutas como a manga e está relacionado à ação de enzimas que atuam sobre compostos da parede celular, à degradação de amido ou à perda de água (Tucker, 1993).

As mudanças na cor da casca foram caracterizadas pelo aumento da nota de 1,5 (coloração verde), por ocasião da colheita, para 3,8 (amareloalaranjado), ao final do armazenamento, sendo independentes da aplicação dos revestimentos (dados não apresentados). Essa variação é explicada pela degradação da clorofila.

Para as variáveis teor de SS e AT, as frutas revestidas não diferiram do controle. $\mathrm{O}$ aumento no teor de SS para $13,0^{\circ}$ Brix e a diminuição da AT até 0,25\% de ácido cítrico ao longo do tempo ocorreram principalmente em temperatura ambiente (Figura 1C).

De maneira semelhante, Yamashita et al. (2001) não observaram influência do uso de embalagens plásticas sobre a AT da manga, durante o armazenamento. Entretanto, o uso de revestimentos com polissacarídeos à base de celulose atrasou 0 amadurecimento da cultivar 'Tommy Atkins', indicado pela maior acidez e firmeza da fruta (Baldwin et al., 1999).

No $20^{\circ}$ dia de armazenamento, verificou-se a presença de defeitos alheios à senescência, que poderiam comprometer a aparência das mangas (Figura 1D). Tratava-se de manchas de coloração vermelha em torno das lenticelas. Sob temperatura ambiente, essas manchas atingiram cerca de $15 \%$ da superfície das frutas, representado pela nota 2,7. Esses danos foram levemente intensificados nas frutas revestidas (Figura 1B). Tal aumento pode ter sido devido à pressão de saída da solução no bico do pulverizador, que pode ter lesionado o tecido da casca. Vale ressaltar que a aparência das frutas, avaliada com base em turgidez e ausência de manchas de senescência, manteve-se compatível com os requisitos de comercialização dos principais mercados até o final do estudo, uma vez que a menor nota, registrada ao $28^{\circ}$ dia, ainda era superior a 2,0 (Figura 1D).

Em adição, verificou-se visualmente maior brilho superficial nos frutos tratados com dextrina e óleo-de-girassol. Este brilho é reconhecido como fator de atração ao consumidor.

Experimento 2: Qualidade pós-colheita de manga 'Tommy Atkins' após aplicação de revestimentos de dextrina contendo óleo-de-girassol
A perda de massa foi influenciada separadamente pelos fatores tempo de armazenamento e revestimentos. $\mathrm{O}$ aumento gradativo da perda de massa, principalmente sob temperatura ambiente, alcançou $12 \%$, aos 30 dias (dados não apresentados). Contudo, a aplicação de dextrina a 2; 3 e $4 \%$ reduziu a perda de massa em 6,4; 6,7 e 6,6\%, respectivamente, em relação ao controle (Figura 2A).

Resultados similares foram obtidos por Carvalho Filho et al. (2006) e Chiumarelli \& Ferreira (2006) com o uso de ceras comestíveis em cerejas e tomates, respectivamente. Diferenças de perdas de massa entre lotes de frutas podem representar redução do volume comercializado, uma vez que se utiliza a massa como referência nas operações de venda.

A firmeza da polpa decresceu durante o período, desde 114,8 até 10,7 N (dados não apresentados), seguindo a resposta observada no experimento 1. Contudo, não atingiu valores tão baixos quanto os verificados naquele experimento, já que as frutas colhidas eram também mais firmes que aquelas do estudo anterior. A diminuição brusca da firmeza após a transferência para a condição ambiente sugere uma provável relação entre esta variável e a perda de massa, além da ação por si só da temperatura sobre o metabolismo da fruta. Porém, as respostas foram diferenciais, dependendo do revestimento aplicado (Figura 2A). As frutas que receberam dextrina foram mais firmes, o que sugere atraso na maturação, ainda que o tratamento a $3 \%$ não diferisse estatisticamente do controle.

Resultados semelhantes foram obtidos por Ribeiro et al. (2007), com a aplicação de revestimento de carragenana enriquecido com cálcio, em morangos, e por Olivas e al. (2007), em maçãs revestidas com alginato de sódio.

É possível que, no experimento anterior, cujos frutos possuíam firmeza cerca de $40 \mathrm{~N}$ inferior por ocasião da colheita, o amaciamento já tenha sido desencadeado, impedindo o efeito dos revestimentos sobre esse evento fisiológico.

Apesar dos baixos valores de luminosidade (L) da casca nos primeiros tempos de avaliação, as frutas tratadas com dextrina a $2 \%$ exibiram maior brilho ao final do período (Figura 2B). Cocozza (2003) também observou aumento na $L$ da casca da manga com o tempo de armazenamento. Por sua vez, Fontes et al. (2007) relataram visível incremento do brilho superficial em maçãs minimamente processadas e recobertas com alginato de sódio.

Os valores de croma (C) da casca nas frutas 
que receberam dextrina a 3\%, foram maiores a partir da mudança da temperatura de armazenamento e até o $28^{\circ}$ dia. Por outro lado, os tratamentos a 2 e $4 \%$ resultaram em cores mais intensas até a última avaliação, quando atingiram, respectivamente, valores de 25,49 e 25,51, bem como apresentaram resposta mais uniforme (dados não apresentados). O valor inicial do C $(15,43)$ aumentou, atingindo 23,07; 25,$49 ; 23,22$ e 25,51, para as frutas do controle e as revestidas com dextrina a 2; 3 e $4 \%$, respectivamente, indicando coloração mais intensa ou pura no final do armazenamento. Mangas 'Kent' tratadas com altas concentrações de $\mathrm{CO}_{2}$ durante curto período apresentaram a resposta de aumento do $\mathrm{C}$ ao longo do tempo (Silva, 2007).

O ângulo de cor $(\mathrm{H})$ da casca foi influenciado separadamente pelo tempo de armazenamento e pelos revestimentos. Sob temperatura ambiente, o $\mathrm{H}$ da casca diminuiu de 100,17 a 80,00, concordando com a redução do teor de clorofila e a exposição de carotenoides já existentes. A resposta, esperada durante o amadurecimento da manga, variou com o tipo de revestimento, de forma que as frutas tratadas com dextrina a 2 e $4 \%$ exibiram coloração amarela mais clara (Figura 2C). No controle, a cor amarela mais escura sugere maturação mais avançada. A resposta assemelha-se às observações de Jomori et al. (2003), que relataram valores maiores de $\mathrm{H}$ em lima-ácida 'Tahiti' submetida à aplicação de ácido giberélico ou do inibidor de etileno 1meticiclopropeno (1-MCP) ou de cera. Porém, Ribeiro et al. (2007) não observaram diferença na cor de morangos tratados com revestimentos.

$\mathrm{O}$ teor de SS aumentou durante o armazenamento, provavelmente devido à conversão do amido em açúcares e à perda de água da polpa, resultando no sabor doce (dados não apresentados). As mudanças ocorreram independentemente da influência dos revestimentos. O aumento no teor de SS foi mais destacado quando as frutas foram transferidas para temperatura ambiente, atingindo 13,2 e 12,3ํix, aos 28 e 30 dias, respectivamente.

As observações concordam com os resultados de Chiumarelli \& Ferreira (2006), em tomates, e de Jacomino et al. (2003), em goiabas tratadas com emulsão de cera-de-carnaúba. Porém, alguns estudos apontam a eficiência dos revestimentos e de embalagens com filmes poliméricos no atraso do acúmulo de SS (Mota et al., 2006; Yamashita et al., 2001).

A redução da AT observada durante o experimento (Figura 2D) pode ser atribuída à respiração e/ou à transformação de ácidos em substratos orgânicos. Esse decréscimo sofreu influência da interação entre os tratamentos, de forma que o uso de dextrina a $4 \%$, em relação aos demais revestimentos, retardou a degradação dos ácidos orgânicos até o $26^{\circ}$ dia. A partir daí, as respostas foram equivalentes às observadas com o uso de dextrina a $2 \%$.

Oliveira \& Cereda (2003) encontraram resultados semelhantes em pêssego revestido com fécula de mandioca e cera de abelha. Em manga 'cat Hoa loc', Hoa \& Ducamp (2008) observaram atraso na degradação de ácidos orgânicos, bem como na evolução da cor, usando revestimento à base de lecitina de soja. Além desta, outras técnicas póscolheita também podem atrasar a degradação de ácidos orgânicos em manga (Cocozza, 2003).

As variações nos teores de substâncias pécticas foram influenciadas pela interação entre os fatores (Figura 2E). O teor inicial de 0,04 g.100 g ${ }^{-1}$ aumentou principalmente nas frutas revestidas com dextrina a $3 \%$ e no controle bem como após a mudança das condições de armazenamento. Na última avaliação, as frutas submetidas à aplicação de dextrina a 2 e $3 \%$ apresentaram os menores teores de substâncias pécticas totais.

Em geral, espera-se diminuição no conteúdo de substâncias pécticas durante o armazenamento e amadurecimento das frutas em razão da ação de enzimas hidrolíticas da parede celular (Tucker, 1993). No entanto, em mangas, as respostas são diferenciadas. Essa diferenciação para o conteúdo de substâncias pécticas também foi observada por Silva (2007) com a cultivar 'Kent', mesmo após tratamentos com alta concentração de $\mathrm{CO}_{2}$.

Análises mais gerais consideram que o aumento no teor de substâncias pécticas seja devido unicamente às alterações na massa fresca da fruta, que, em razão da perda de água, concentra os diversos solutos. Porém, sugere-se a realização de estudos bioquímicos/moleculares mais detalhados para caracterizar e compreender os mecanismos que regulam os teores de substâncias pécticas e o amaciamento da polpa, em manga.

No que se refere à aparência das mangas, manteve-se praticamente inalterada até o $23^{\circ}$ dia, quando a menor nota observada foi de 3,6 (dados não apresentados). Considerando todo o período, o uso de dextrina a $2 \%$ permitiu a manutenção da aparência durante os 30 dias de armazenamento. No $26^{\circ}$ dia, as frutas do controle apresentavam notas de 2,9 , enquanto naquelas tratadas com dextrina a $2 \%$ o valor era de 3,8.

Adicionalmente, no $23^{\circ}$ dia de avaliação, pôde-se observar uma intensificação das manchas vermelhas em torno das lenticelas (Figura 2F). As 
frutas tratadas com dextrina $4 \%$ mostraram-se mais suscetíveis ao aparecimento dessas manchas, no entanto aquelas que receberam dextrina a $3 \%$ mantiveram melhor nota, superior a 3,0.

Silva (2007), no seu estudo com mangas 'Tommy Atkins' submetidas a 15 e $20 \%$ de $\mathrm{CO}_{2}$, mencionou maior comprometimento dos danos às lenticelas nas frutas tratadas, caracterizando-os pela aparência ressecada e por pontuações escuras na superfície.

Algumas condições de campo, como pulverizações, colheita e transporte inadequados, e o descuido do manejo pós-colheita da manga podem provocar danos às lenticelas. Este dano pode não ser perceptível imediatamente após a lavagem e a aplicação dos tratamentos pós-colheita comerciais da fruta, mas pode aparecer durante o armazenamento e a comercialização (Choudhury \& Costa, 2004).

Em adição, foi observada a formação de placas na superfície das frutas revestidas com dextrina a $4 \%$, provavelmente devido à menor solubilidade do composto em água, nessa concentração. Portanto, essa concentração, mesmo associada ao óleo-degirassol, não formou uma película contínua na superfície da manga, prejudicando sua avaliação visual.

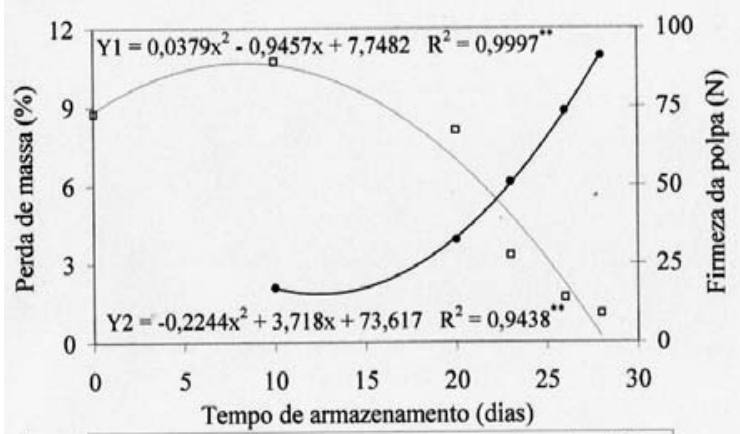

A

- perda de massa (Y

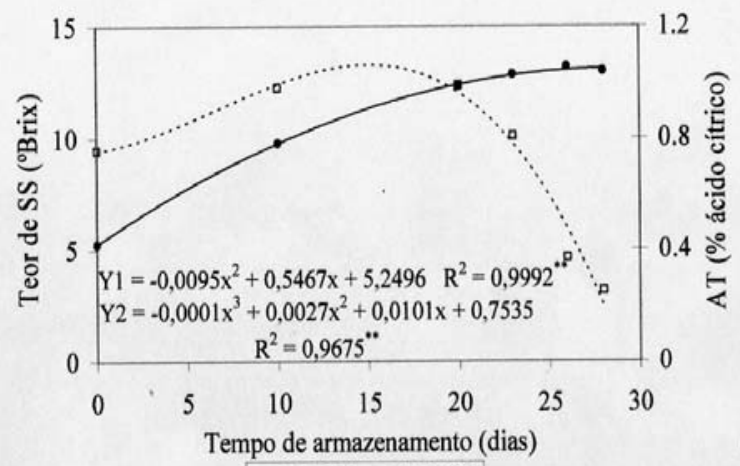

- SS (Y1) ० AT (Y2)

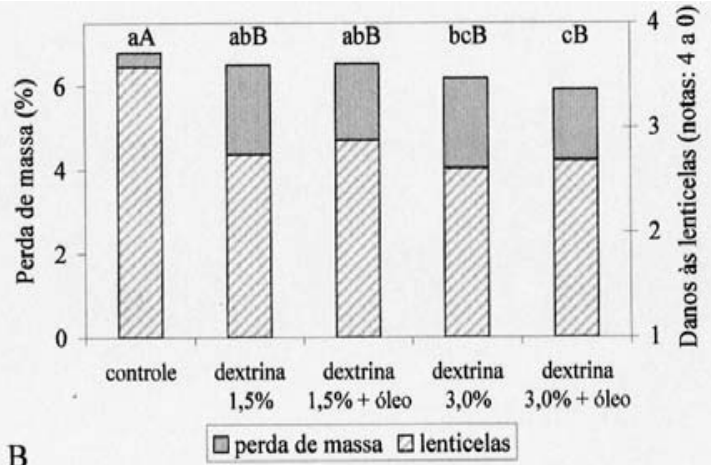

B

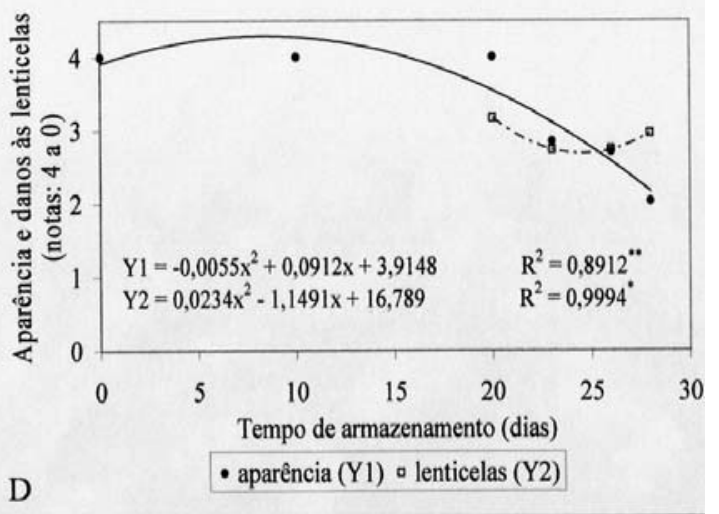

FIGURA 1 - Perda de massa (A e B), firmeza da polpa (A), teor de sólidos solúveis - SS - (C), acidez titulável -AT - (C), aparência (D) e ocorrência de danos às lenticelas (B e D) de manga 'Tommy Atkins' submetida à aplicação de dextrina, com ou sem óleo-de-girassol, durante até 20 dias de armazenamento refrigerado $\left(11,7 \pm 3,1^{\circ} \mathrm{C}\right.$ e $\left.79 \pm 8 \% \mathrm{UR}\right)$, seguidos de até 8 dias em temperatura ambiente $\left(21,3 \pm 2,6^{\circ} \mathrm{C}\right.$ e $\left.48 \pm 8 \% \mathrm{UR}\right)$. Em $\mathrm{B}$, as médias de perda de massa e danos às lenticelas seguidas, respectivamente, por letras minúsculas ou maiúsculas iguais não diferem entre si, pelo teste de Tukey $(\mathrm{P} \leq 0,05)$. 


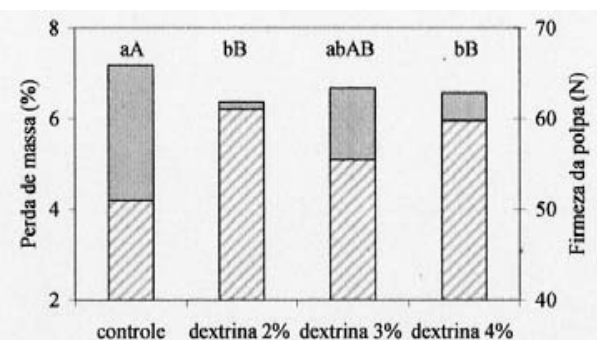

A

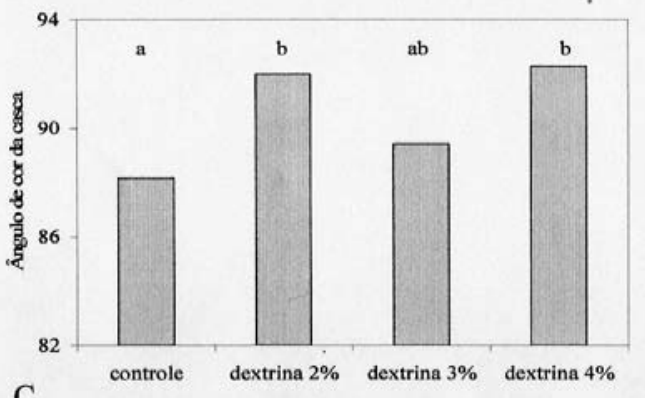

C

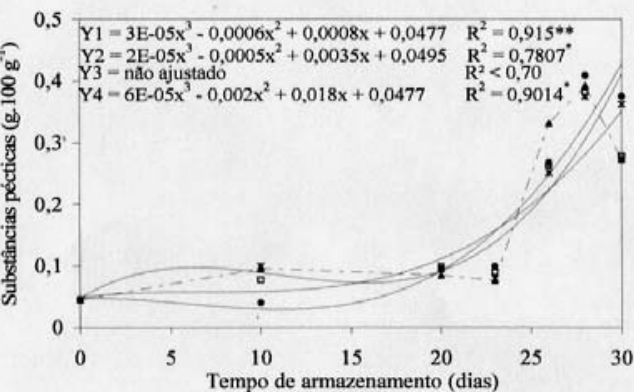

E : controle (Y1) dextrina $3 \%(\mathrm{Y} 3)$

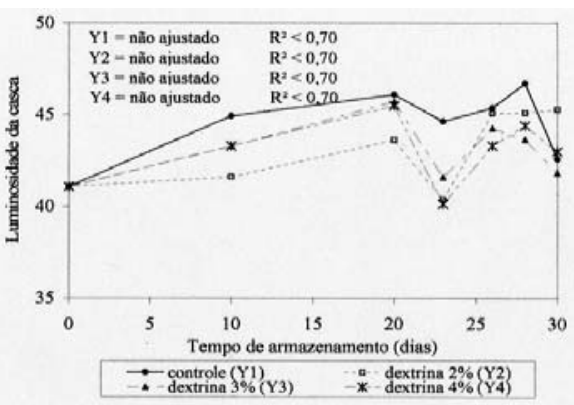

B

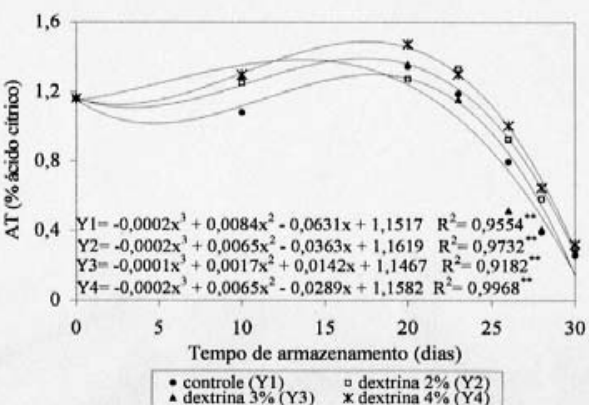

$\mathrm{D}$

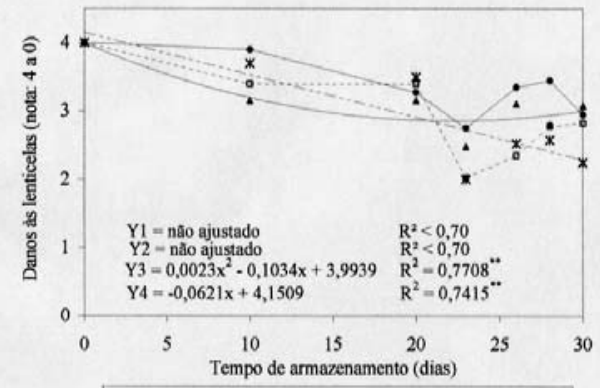

F

FIGURA 2 - Perda de massa (A), firmeza da polpa (A), luminosidade da casca (B), ângulo de cor da casca (C), acidez titulável - AT - (D), teor de substâncias pécticas (E) e ocorrência de danos às lenticelas (F) de manga ‘Tommy Atkins’ submetida à aplicação de dextrina, contendo óleo de girassol a $0,4 \%$, durante até 20 dias de armazenamento refrigerado $\left(11,7 \pm 3,1^{\circ} \mathrm{C}\right.$ e $\left.87 \pm 6 \% \mathrm{UR}\right)$, seguidos de até 10 dias em temperatura ambiente $\left(23,1 \pm 2,1^{\circ} \mathrm{C}\right.$ e $\left.56 \pm 7 \% \mathrm{UR}\right)$. Em A e C, médias de perda de massa e ângulo de cor da casca seguidas por letras minúsculas iguais ou de firmeza da polpa seguidas por letras maiúsculas iguais não diferem entre si, pelo teste de Tukey $(\mathrm{P} \leq$ $0,05)$.

\section{CONCLUSÃO}

O uso de revestimentos de dextrina a $2 \%$ contendo óleo de girassol a $0,4 \%$ manteve a qualidade da manga 'Tommy Atkins' durante 20 dias de armazenamento refrigerado, seguido de até 10 dias em temperatura ambiente.

\section{REFERÊNCIAS}

ANUÁRIOBRASILEIRODAFRUTICULTURA2007. Santa Cruz do Sul: Editora Gazeta Santa Cruz, 2007. 136p.

AOAC. Association of Official Analytical Chemists. Official methods of analysis. $11^{\text {th }}$ ed. Washington, 1992.1115p. 
BALDWIN, E.A.; BURNS, J.K.; KAZOKAS, W.; BRECHT, J.K.; HAGENMAIER, R.D.; BENDER, R.J.; PESIS, E. Effect of two edible coatings with different permeability characteristics on mango (Mangifera indica L.) ripening during storage. Postharvest Biology and Technology, Amsterdam, v.17, n.3, p.215226, 1999.

BLUMENKRANTZ, N.; ASBOE-HANSEN, G. New method for quantitative determination of uronics acids. Analytical Biochemistry, New York, v.54, n.2, p.484-489, 1973.

CARVALHO FILHO, C.D.C.; HONÓRIO, S.L.; GIL, J.M. Qualidade pós-colheita de cerejas cv Ambrunés utilizando coberturas comestíveis. Revista Brasileira de Fruticultura, Jaboticabal, v.28, n.2, p.180-184, 2006.

CHIUMARELLI, M.; FERREIRA, M. D. Qualidade pós-colheita de tomates 'Débora' com utilização de diferentes coberturas comestíveis e temperaturas de armazenamento. Horticultura Brasileira, Brasília, v.24, n.3, p.381-385, 2006.

CHOUDHURY, M.M.; COSTA, T.S. da. Perdas na cadeia de comercialização da manga. Petrolina-PE: Embrapa Semiárido, 2004. 41p.

COCOZZA, F.D.M. Maturação e conservação de manga 'Tommy Atkins' submetida à aplicação póscolheita de 1-metilciclopropeno. 2003. 175f. Tese (Doutorado em Engenharia Agrícola) - Universidade Estadual de Campinas, Campinas, 2003.

EMEX. Norma de calidad para mango fresco de exportación. CIAD: Zapopan, 1998.

FONTES, L.C.B.; SARMENTO, S.B.S.; SPOTO, M.H.F. Características sensoriais e microbiológicas de maças minimamente processadas recobertas com películas. Ciência e Tecnologia de Alimentos, Campinas, v.27, n.1, p.91-98, 2007.

HENRIQUE, C.M.; CEREDA, M.P.; SARMENTO, S.B.S. Características físicas de filmes biodegradáveis produzidos a partir do amido modificado de mandioca. Ciência e Tecnologia de Alimentos, Campinas, v.28, n.1, p.231-240, 2008.

HOA, T.T.; DUCAMP, M.N. Effects of different coatings on biochemical changes of 'cat Hoa loc' mangoes in storage. Postharvest Biology and Technology, Amsterdam, v.48, n.1, p.150-152, 2008.
JACOMINO, A.P.; OJEDA, R.M.; KLUGE, R.A.; SCARPARE FILHO, J.A. Conservação de goiabas tratadas com emulsões de cera de carnaúba. Revista Brasileira de Fruticultura, Jaboticabal, v.25, n.3, p.401-405, 2003.

JOMORI, M.L.L.; KLUGE, R.A.; JACOMINO, A.P.; TAVARES, S. Conservação refrigerada de lima-ácida 'Tahiti': uso de 1-metilciclopropeno, ácido giberélico e cera. Revista Brasileira de Fruticultura, Jaboticabal, v.25, n.3, p.406-409, 2003.

LIMA, M.A.C. de; TRINDADE, D.C.G. da; SANTOS, A.C.N. dos; PAES, P. de C. Armazenamento refrigerado de manga 'Tommy Atkins' sob atmosfera modificada (Smartbag ${ }^{\mathrm{TM}}$ ). In: CONGRESO IBEROAMERICANO DE TECNOLOGÍA POSTCOSECHA Y AGROEXPORTACIONES, 5. 2007, Cartagena. Artigos completos... Cartagena: GPR/AITEP, 2007.p.1288-1296.

LUCENA, A.P.; OJEDA, R.M.; KLUGE, R.A.; SCARPARE FILHO, J.A. Conservação de goiabas tratadas com emulsões de cera-de-carnaúba. Revista Brasileira de Fruticultura, Jaboticabal, v.25, n.3, p.401-405, 2003.

McREADY, P.M.; McCOMB, E.A. Extraction and determination of total pectin materials. Analytical Chemistry. Columbus, v.24, n.12, p.1586-1588, 1952.

MORAIS, P.L.D. de; FILGUEIRAS, H.A.C.; PINHO, J.L.N. de; ALVES, R.E. Ponto de colheita ideal de mangas 'Tommy Atkins' destinadas ao mercado europeu. Revista Brasileira de Fruticultura, Jaboticabal, v.24, n.3, p.671-675, 2002.

MOTA, W.F. da; SALOMÃO, L.C.C.; NERES, C.R.L.; MIZOBUTSI, G.P.; NEVES, L.L. de M. Uso de cerade-carnaúba e saco plástico poliolefínico na conservação pós-colheita do maracujá-amarelo. Revista Brasileira de Fruticultura, Jaboticabal, v.28, n.2, p.190-193, 2006.

OLIVAS, G.I.; MATTINSON, D.S.; BARBOSACÁNOVAS, G.V. Alginate coatings for preservation of minimally processed 'Gala' apples. Postharvest Biology and Technology, Amsterdam, v.45, n.1, p.8996, 2007.

OLIVEIRA, M.A.; CEREDA, M.P. Pós-colheita de pêssegos (Prunus persica Bastsch) revestidos com filmes à base de amido como alternativa à cera comercial. Ciência e Tecnologia de Alimentos, 
Campinas, v.23, p.28-33, 2003. Suplemento

RIBEIRO, C.; VICENTE, A.A.; TEIXEIRA, J.A.; MIRANDA, C. Optimization of edible coating composition to retard strawberry fruit senescence. Postharvest Biology and Technology, Amsterdam, v.44, n.1, p.63-70, 2007.

SILVA, A.L. da. Conservação pós-colheita de mangas 'Tommy Atkins'e 'Kent' produzidas no Vale do São Francisco mantidas sob refrigeração e submetidas a diferentes consentrações de $\mathrm{CO}_{2}$ por curto período de tempo. 2007. 124 f. Dissertação (Mestrado) Universidade Federal da Paraíba, João Pessoa, 2007.

TUCKER, G.A. Introduction. In: SEYMOUR, G.B.; TAYLOR, J.E.; TUCKER, G.A. Biochemistry of fruit ripening. London: Chapmal \& Hall, 1993. p.2-51.

VALEXPORT. Há 19 anos unindo forças para o desenvolvimento do Vale do São Francisco e da fruticultura brasileira. Petrolina, 2008. 17p.
WHITE JUNIOR, D.R.; HUDSON, P.; ADAMSON, J.T. Dextrin characterization by high-performance anion-exchange chromatography-pulsed amperometric detection and size-exclusion chromatography-multi-angle light scatteringrefractive index detection. Journal of Chromatography A, Amsterdam, v.997, n.1-2, p.7985, 2003.

WILLS, R. B. H.; McGLASSON, W. B.; GRAHAM D.; JOYCE, D. C. Postharvest: an introduction to the physiology and handling of fruit, vegetables and ornamentals. 5.ed. Wallingford: New South Wales University Press, 2007. 227p.

YAMASHITA, F.; TONZAR, A.C.; FERNANDES, J.G.; MORIYA, S.; BENASSI, M. de T. Embalagem individual de mangas cv. Tommy Atkins em filme plástico: efeito sobre a vida de prateleira. Revista Brasileira de Fruticultura, Jaboticabal, v.23, n.2, p.288-292, 2001. 